\title{
Near Simultaneous Release of Classical and Peptide Cotransmitters from Chromaffin Cells
}

\author{
Matthew D. Whim \\ Department of Biology, Pennsylvania State University, State College, Pennsylvania 16802
}

\begin{abstract}
Adrenal chromaffin cells are an important part of the neuroendocrine system and under stressful conditions release catecholamines into the blood, thus regulating many physiological processes. In addition to the catecholamines, chromaffin cells also synthesize a range of peptides, including neuropeptide Y. Although the catecholamines and peptides are both contained within dense core granules, whether they are copackaged is less clear. Here, I investigate whether a single dense core granule can be loaded with both types of transmitter molecules. Using amperometry and FMRFamide tagging, I simultaneously measure the secretion of the catecholamines and a neuropeptide from mouse chromaffin cells in vitro. I find that fusion of a single dense core granule releases both types of transmitters into the extracellular space. Significant amounts of peptide escape from a fusing granule in 1-2 ms: almost as rapidly as the catecholamines. This suggests that the kinetics of peptide secretion might not be as sluggish as sometimes thought.
\end{abstract}

Key words: large dense core granule; peptide; secretion; cotransmitters; chromaffin; neuropeptide Y

\section{Introduction}

Most neurons and neuroendocrine cells contain several classes of transmitters. Fast-acting classical transmitters are generally packaged into small vesicles, whereas slower-acting transmitters are found within large dense core granules (LDCGs). The latter enclose a chemically diverse array of transmitters but commonly contain neuropeptides. However, LDCGs can also contain other transmitter types, including nucleotides and serotonin (Bruns et al., 2000; Obermuller et al., 2005).

This leads to the question of whether a single LDCG can contain multiple classes of transmitters. Studies at the EM level have shown that an LDCG can contain different neuropeptides (Kreiner et al., 1986; Zhang et al., 1993). However, whether a single LDCG can contain neuropeptides and small molecule transmitters is less clear. For example, it has been suggested that LDCGs in pancreatic $\beta$-cells contain GABA and insulin (Gammelsaeter et al., 2004). Although coexistence in a single granule remains an open question, it is clear that several populations of LDCGs can exist within a single cell. Peptides on the same prohormone usually end up in the same LDCGs, but peptides on different precursors can be packaged into different LDCGs (Dacheux, 1981; Zhang et al., 1993; Glombik and Gerdes, 2000). More rarely, peptides on the same precursor can be packaged into different LDCGs (Fisher et al., 1988).

In addition to the variability in packaging, LDCG fusion can

Received Nov. 30, 2005; revised May 17, 2006; accepted May 17, 2006.

This work was supported by National Institutes of Health Grant 5R21 NS047543 and by start-up funds from Pennsylvania State University. I thank Guy Moss and Abigail May for making the FMRFamide-tagged expression plasmid, June Liu and Guy Moss for critically reading this manuscript, and Chris Levan (Cytec Industries, West Paterson, NJ) for generously donating carbon fibers.

Correspondence should be addressed to Matthew D. Whim, Department of Biology, 208 Mueller Building, Pennsylvania State University, State College, PA 16802. E-mail: mdw13@psu.edu.

D01:10.1523/JNEUROSCI.5100-05.2006

Copyright $\odot 2006$ Society for Neuroscience $\quad$ 0270-6474/06/266637-06\$15.00/0 also be regulated. Peptide secretion generally occurs at elevated firing frequencies (Urban and Randic, 1984; Whim and Lloyd, 1989), and complete release probably occurs when there is full fusion with the cell membrane (but see Angleson et al., 1999). However, LDCGs can also make transient connections with the cell membrane, allowing partial release of the granular contents. These connections can restrict the type (Barg et al., 2002) or amount (Perrais et al., 2004) of transmitter that is released. Regulation of the fusion pore appears to be a point at which release from LDCGs is controlled (Graham et al., 2002; Fulop et al., 2005).

These studies indicate that there is modulation of the trafficking and fusion steps. However, functional evidence for corelease of different transmitters is sparse. Can a single LDCG contain peptides and small molecule transmitters? If so, are these transmitters coreleased? What are the relative kinetics of transmitter release?

Here, I address these questions using chromaffin cells. These neuroendocrine cells are packed with LDCGs containing the catecholamines (Blaschko and Welch, 1953). Chromaffin cells also synthesize a number of peptides including neuropeptide Y (NPY) (Henion and Landis, 1990). Using amperometry and FMRFamide tagging of the NPY precursor, I simultaneously measure the release of the catecholamines and a peptide from chromaffin cells in culture. In transfected cells, a single LDCG is found to contain both types of transmitter, and these chemically distinct molecules are released contemporaneously with rapid, millisecond, kinetics.

\section{Materials and Methods}

Cell culture. Chromaffin cells were cultured (Whim and Moss, 2001) from C57BL/6 mice [postnatal day 18 (P18) to P29], and then transfected after $6-24 \mathrm{~h}$ with $0.2 \mu \mathrm{g}$ of pGFP, $0.65 \mu \mathrm{g}$ of $\mathrm{pNPY}(\mathrm{G} / \mathrm{L}) .2 \mathrm{Fa}$, and $0.65 \mu \mathrm{g}$ of pFaNaCh (a FMRFamide receptor) using Lipofectamine 2000. The FMRFamide-tagged NPY prohormone (Whim and Moss, 2001) had two 
new modifications: first, another copy of FMRFamide was inserted before the stop codon; second, the glycine residue at the $\mathrm{C}$ terminus of NPY was mutated to leucine. The tagged prohormone thus encodes two copies of FMRFamide and one of nonamidated NPY. The first modification was designed to increase the levels of synthesized FMRFamide. The second modification was designed to prevent activation of any endogenous NPY receptors by secretion of the overexpressed NPY (because the terminal amide is required for NPY receptor activation). After transfection, $0.5 \mu \mathrm{M}$ TTX was added to the culture. Cells were used 3-4 d later.

Electrophysiology. Voltage-clamp recordings were made with a Multiclamp 700A amplifier (Molecular Devices). Cells were superfused with extracellular solution containing (in $\mathrm{mM}$ ) $135 \mathrm{NaCl}, 3 \mathrm{KCl}, 2 \mathrm{CaCl}_{2}, 1 \mathrm{MgCl}_{2}, 10$ HEPES, and 11 glucose, $\mathrm{pH} 7.3$, with $\mathrm{NaOH}$. In some experiments, $2 \mathrm{mM} \mathrm{CaCl}_{2}$ was replaced by $5 \mathrm{~mm}$ $\mathrm{CaCl}_{2}$ or $2 \mathrm{mM} \mathrm{BaCl}_{2}$ to increase release. The whole-cell pipette solution contained (in $\mathrm{mm}$ ) $120 \mathrm{~K}$-acetate, $15 \mathrm{KCl}, 5 \mathrm{NaCl}, 10$ HEPES, 4 MgATP, 0.3 NaGTP, and 1 Na cAMP, pH 7.2, with $\mathrm{KOH}$. A few recordings were made using the perforated patch technique in which the pipette solution contained $600 \mu \mathrm{g} / \mathrm{ml}$ amphotericin B (and lacked ATP, GTP, and cAMP). Pipette resistance was $\sim 6 \mathrm{M} \Omega$, and no compensation was applied. Access resistance was typically $15-25 \mathrm{M} \Omega$ leading to a voltage error of $<2 \mathrm{mV}$ for the largest secretory currents. Secretion was triggered with depolarizing steps from -80 to $+20 \mathrm{mV}$ for $0.5-1$ s at $0.1 \mathrm{~Hz}$.

Amperometric recordings were made using polyethylene-insulated carbon fiber electrodes and T650 fibers (Cytec Industries, West Paterson, $\mathrm{NJ})$. The fiber was held at $+700 \mathrm{mV}$ using the second headstage of the amplifier. Amperometric (and membrane) currents were sampled at $5 \mathrm{kHz}$ and filtered at $2 \mathrm{kHz}$. Experiments indicated that application of $0.2 \mu \mathrm{M}$ FMRFamide or NPY did not generate an amperometric current (data not shown).

Simultaneous measurements of peptide and catecholamine secretion were made from isolated GFP-positive chromaffin cells. Secretory currents were analyzed using pClamp 9 (Molecular Devices), OriginPro 7 (Microcal Software, Northampton, MA), and Excel (Microsoft, Seattle, WA). Statistical significance was assessed using the Mann-Whitney $U$ test.

Immunocytochemistry. Cells were stained as described previously (Whim and Moss, 2001). Primary antibodies were sheep anti-dopamine $\beta$ hydroxylase ( $\mathrm{D} \beta \mathrm{H} ; 1: 2500$; Affinity BioReagents, Golden, $\mathrm{CO}$ ), rabbit anti-NPY (1:40,000; Peninsula Laboratories, Belmont, CA) and rabbit anti-FMRFamide [1:20,000 (Peninsula Laboratories); this dilution was not sufficient to stain an endogenous peptide(s) that was otherwise observed in nontransfected cells (unpublished observation)]. Secondary antibodies were donkey anti-sheep tetramethylrhodamine isothiocyanate (TRITC; 1:50; Jackson ImmunoResearch, West Grove, PA), donkey anti-rabbit Alexa 488 (1:200; Invitrogen, Eugene, OR), and swine antirabbit TRITC (1:40; Dako, High Wycombe, UK). In colabeling experiments, antibodies were applied sequentially, with anti- $\mathrm{D} \beta \mathrm{H}$ applied first. Images were obtained with a Nikon (Tokyo, Japan) TE 2000U or an Olympus (Tokyo, Japan) IX-70 microscope $(60 \times 1.4$ numerical aperture oil-immersion objective).

The punctate NPY staining (see Fig. 1) was eliminated by preincubation with $10 \mu \mathrm{M}$ NPY but not with $10 \mu \mathrm{M}$ met-enkephalin (a neuropeptide that is also synthesized in chromaffin cells) (Henion and Landis,
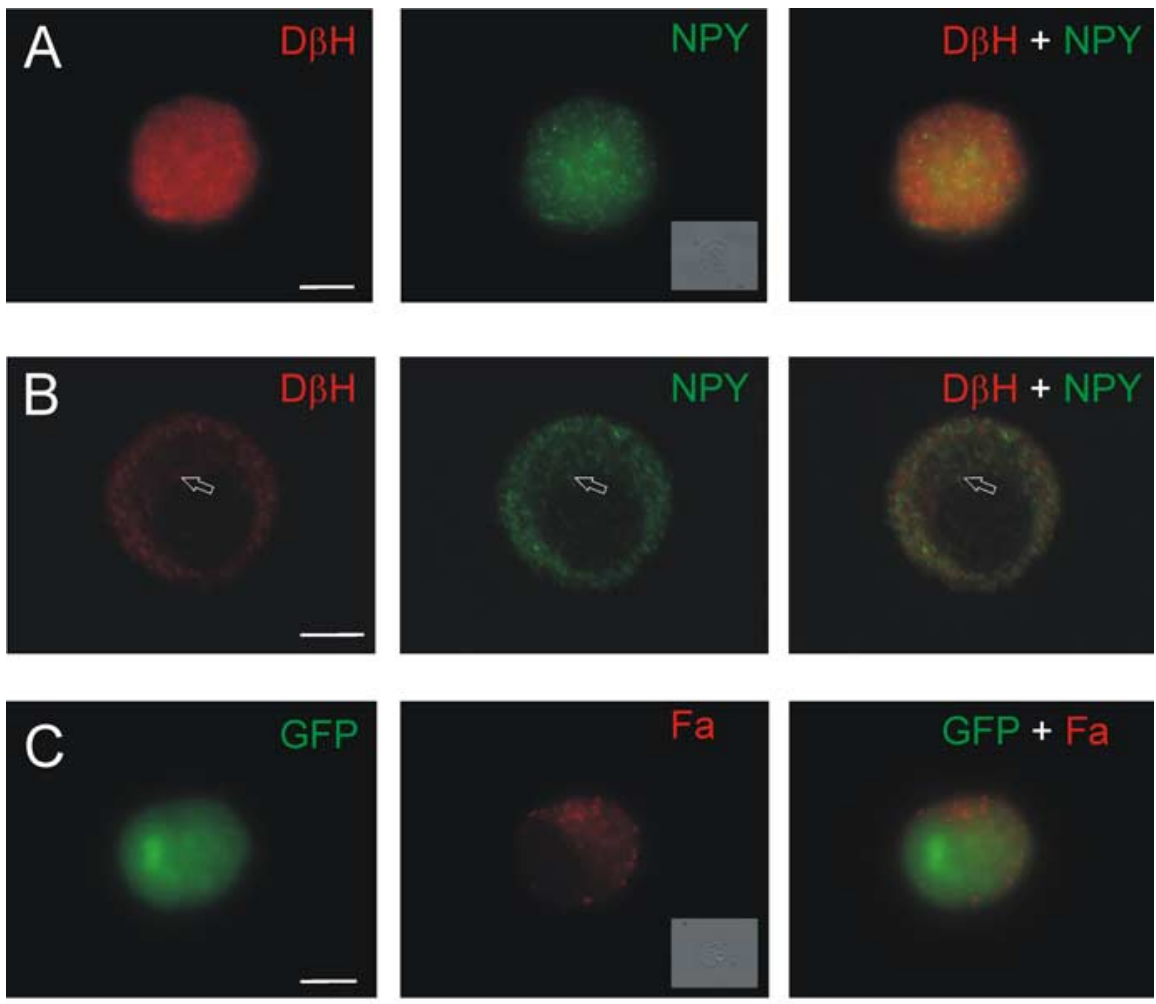

Figure 1. Markers of catecholamines and peptides are found in the same chromaffin cells. $A$, Example of a chromaffin cell that was double stained with antibodies for D $\beta H$ (left) and NPY (middle). Right, Merged image. $\boldsymbol{B}$, Single confocal slice indicates that (a) to puncta. Right, Merged image. D, A nontransfected, GFP-negative cell (left) is not FMRFamide immunoreactive (right; see Materials and Methods). $A, C, D$, Insets, Bright-field images of each cell. Scale bars, $5 \mu \mathrm{m}$.

1990). Similar punctate NPY staining was also seen using two alternate anti-NPY antibodies [sheep anti-NPY, 1:200, from Chemicon (Temecula, CA) and goat anti-NPY, 1:100, from Santa Cruz Biotechnology (Santa Cruz, CA)].

Control experiments showed there was no significant bleed-through of the two fluorescent labels or cross-reactivity between antibodies.

\section{Results}

Chromaffin cells synthesize classical and peptide transmitters Rat chromaffin cells contain NPY (Henion and Landis, 1990). To determine whether mouse chromaffin cells are NPY immunoreactive, cells were costained with antibodies recognizing NPY and dopamine $\beta$ hydroxylase. $\mathrm{D} \beta \mathrm{H}$, an enzyme involved in catecholamine synthesis, is associated with the LDCG membrane (Lewis and Asnani, 1992). As anticipated, all chromaffin cells were immunoreactive for $\mathrm{D} \beta \mathrm{H}$. Unexpectedly, all chromaffin cells were also NPY positive (Fig. 1A). Confocal images indicated that the staining for both antigens was punctate, and occasional overlap was observed (Fig. $1 B$ ). However, given the density of the staining, overlap might be expected to occur by chance. Thus, another way was sought to determine whether there was functional colo- 

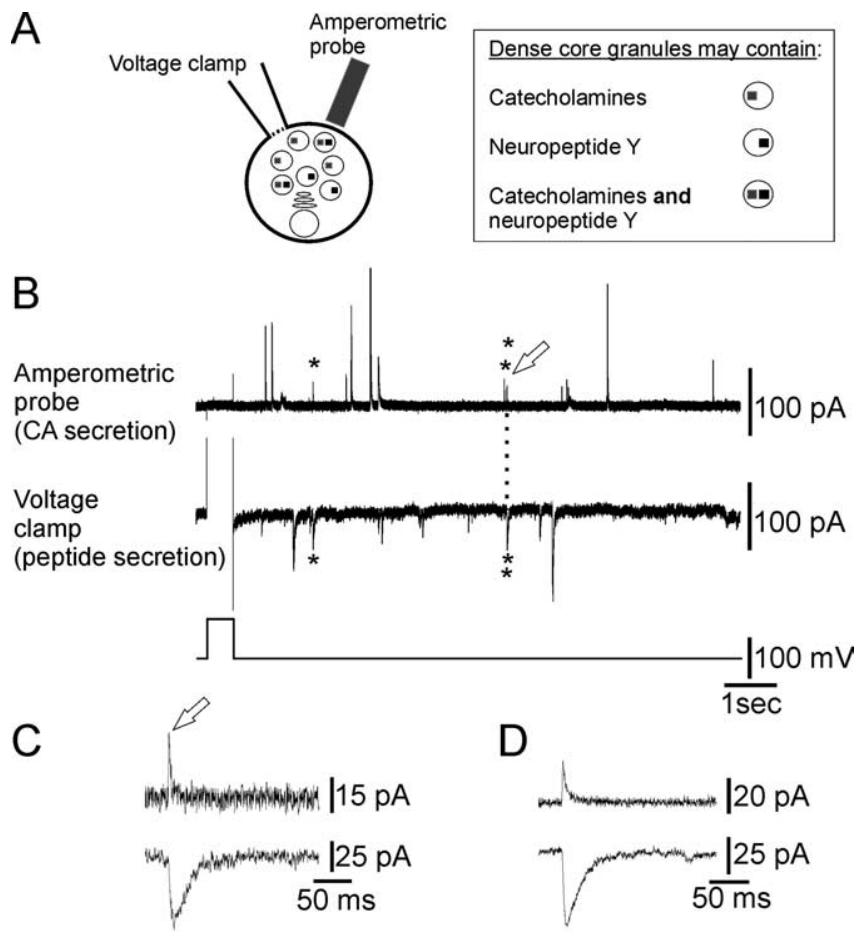

E

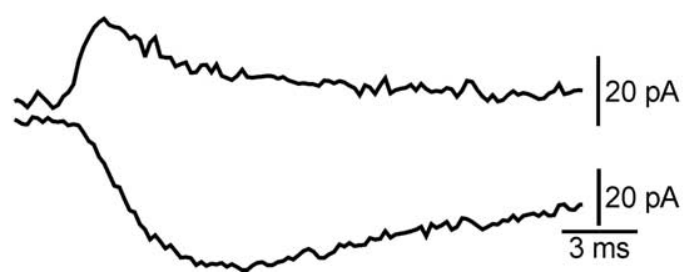

Figure 2. Classical and peptide transmitters are coreleased from chromaffin cells. $\boldsymbol{A}$, Schematic of the experimental arrangement. $\boldsymbol{B}$, Secretion was evoked from a single voltageclamped chromaffin cell by changing the membrane potential from -80 to $+20 \mathrm{mV}$ for $0.5 \mathrm{~s}$ (bottom trace). Rapid inward membrane currents (middle trace) reflect the secretion of the peptide tag and rapid outward amperometric currents (top trace) reflect the secretion of catecholamines (CA). Three secretory events (asterisks) occur simultaneously. C, Co-occurring secretory events (open arrow) from the experiment shown in $\boldsymbol{B}$ on an extended time scale. $\boldsymbol{D}$, Average of all $(n=8)$ co-occurring secretory events from the cell shown in $\boldsymbol{B}$. $\boldsymbol{E}$, Average events shown in $\boldsymbol{D}$ on an extended time scale.

calization and release of classical and peptide transmitters from single LDCGs.

\section{Amperometry and FMRFamide tagging measure the secretion of two types of transmitters}

To address this question, I took an electrophysiological approach in which the secretion of the catecholamines and neuropeptide was followed in real time. NPY secretion was monitored using the FMRFamide-tagging technique (Whim and Moss, 2001) and catecholamine release by amperometry (Wightman et al., 1991).

In the FMRFamide-tagging method, chromaffin cells are transfected with several plasmids: the first encodes the NPY prohormone, which has been tagged with the coding sequence for a small neuropeptide, FMRFamide. Expression of the tagged NPY prohormone results in the synthesis of both NPY and FMRFamide. A second plasmid encodes the ionotropic FMRFamide receptor. Stimulation of a transfected cell results in the cosecretion of NPY and FMRFamide (the tag) because they are stored in the same LDCGs (Whim and Moss, 2001). The secreted FMRFamide activates the ionotropic FMRFamide receptors on the sur-
A

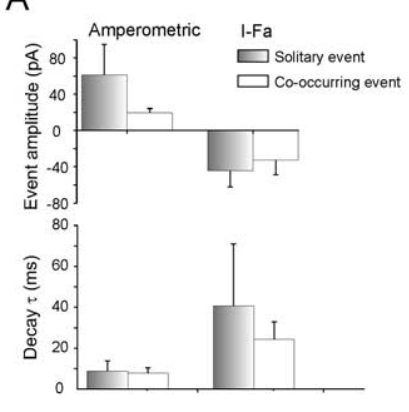

B
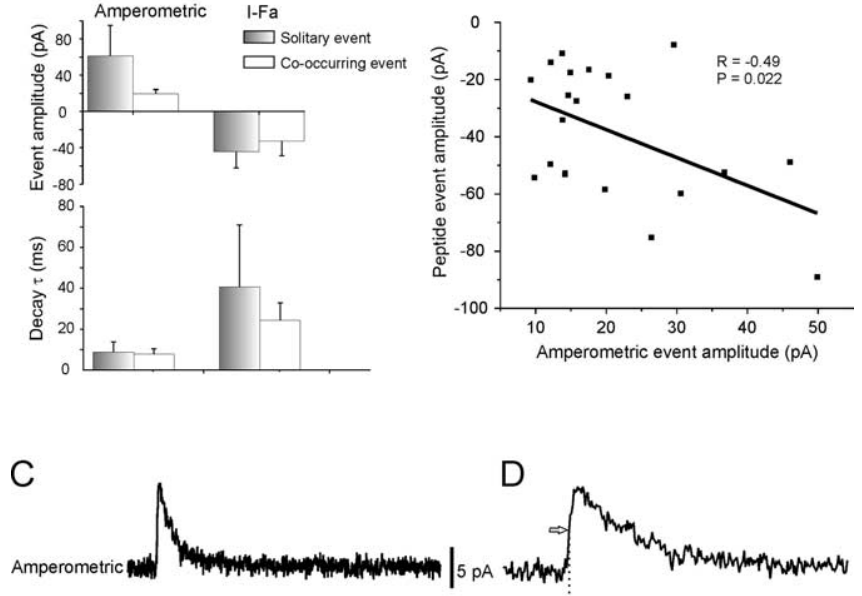

Voltage clamp
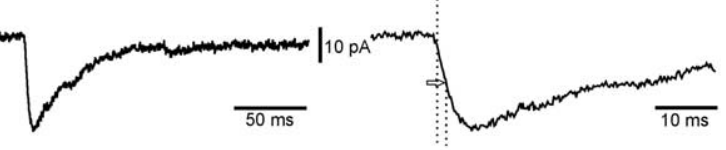

$\Delta \mathrm{t}_{\text {half-amplitude }}=1.5 \mathrm{~ms}$

Figure 3. Characteristics of the co-occurring amperometric and peptide secretory events. $A$, Measuring the amplitude and decay kinetics of the amperometric and peptide secretory events indicates that there is no significant difference in the characteristics of events that occur simultaneously ("co-occurring") or "solitary" events ( $p>0.05$ ). I-Fa, Peptide secretory events. $\boldsymbol{B}$, Relationship between the amplitude of the co-occurring catecholamine and peptide events ( $n=21$ events from 4 cells) indicates that there is statistically significant, positive relationship between the two. The line is a fitted linear regression. $C, D$, Average of all co-occurring secretory events ( $n=21$ events from 4 cells) indicates that although the peak of the secretory events are offset, the rising phases and time at half-amplitude (arrows) occur almost simultaneously. Note the difference in time scales between $\boldsymbol{C}$ and $\boldsymbol{D}$.

face of the same cell, resulting in an "autaptic" secretory current reflecting the cosecretion of NPY. This method can track peptide secretion with a millisecond time resolution. Punctate FMRFamide immunoreactivity is seen in the transfected GFP-positive cells (Fig. 1C,D).

The secretion of the catecholamines was monitored using amperometry, an approach which relies on the oxidizable nature of the catecholamines to generate a current whose amplitude and kinetics reflect the release of these transmitters through the fusion pore (Mosharov and Sulzer, 2005).

The experimental configuration is shown in Figure $2 \mathrm{~A}$. Theoretically, three types of granules could exist: granules that contain the catecholamines, granules that contain NPY, or granules that contain the catecholamines and NPY. Fusion of the latter type under the amperometric probe would give a simultaneous amperometric signal and peptidergic autaptic current.

\section{Corelease of catecholamines and a peptide from a single LDCG}

In the cell shown in Figure $2 B$, a depolarizing step evoked secretion of catecholamines as revealed by the amperometric current transients (top trace) and peptide as indicated by the inward autaptic currents (middle trace). Closer examination showed that three catecholamine and peptidergic secretory events occurred proximately in time (asterisks). The third of these events is displayed in Figure 2C. The close correspondence in the time course of the two events reflects the cosecretion of the catecholamines and peptide from a single dense core granule (see below). In this cell, eight secretory events occurred closely in time, and the average of these events (Fig. 2D,E) indicates that 
the peak of the peptide secretory event was delayed compared with the peak of the amperometric event.

From Figure $2 B$, it can be seen that in addition to co-occurring catecholamine and peptidergic events, there are solitary events of both types. The reasons for this are examined below (see Discussion). To determine whether the granules that contain the tag are different from the remainder of the granule population, solitary amperometric events were compared with amperometric events that co-occurred with peptidergic events (Fig. $3 A$ ). The amplitude and decay kinetics of these two populations were not significantly different. This suggests that the FMRFamidetagging technique does not modify synthesis and packaging of the catecholaminergic LDCGs. Similarly, there was no difference in the characteristics of solitary peptidergic events or those that co-occurred with amperometric events (Fig. $3 A$ ).

However, a plot of the amplitude of the co-occurring events revealed a weakly positive correlation between the two (Fig. 3B). This implies that the levels of both transmitters change in parallel, suggesting that peptide and catecholamines are stored at a constant concentration, as shown for other LDCGs (Bruns et al., 2000).

\section{Catecholamines and peptides are released from a fusing granule at comparable times}

The kinetics of an amperometric event reflects the rate of catecholamine release from a fusing granule (Mosharov and Sulzer, 2005). Similarly, the rising phase of the peptidergic current indicates the time at which the peptide tag starts to escape from the fusing granule. Comparing the rising phases of the two types of events allows an estimate of the time course of release from a single granule to be made. Thus, co-occurring events were averaged, and the start time was compared for the two types of secretory events. Using this approach, the peptidergic event was found to be delayed by $0.1 \pm 1.2 \mathrm{~ms}$ compared with the amperometric event (Fig. $3 C, D)$ (mean $\pm \mathrm{SD}, n=4$ cells). Even the delay at half-maximal amplitude was only $1.5 \mathrm{~ms}$, indicating that significant catecholamine and peptide secretion occurred in $<2 \mathrm{~ms}$ (Fig. 3D).

An important control was to determine whether overlap of the two types of events was significant. In the subset of cells that had co-occurring events (those initiated within $5 \mathrm{~ms}$ ), 14\% of the amperometric spikes co-occurred with peptide events ( 21 of 145 events). Could cosecretion occur by chance? To investigate this possibility, a perievent histogram was constructed by measuring the time intervals between each peptidergic event and the amperometric events that immediately preceded and followed it. A clear peak is seen in this distribution (Fig. $4 A$ ) at the $0-5 \mathrm{~ms}$ bin in agreement with the amperometric-peptidergic delay noted above (if overlap occurred randomly, then no peak should be observed because it would be equally likely for any given amperometric event to precede or follow a peptidergic event). A second estimate of the probability that a peptidergic event could occur during the rise time of an amperometric event was calculated from the following: $P_{\text {(time interval) }}=1-e^{-t / \tau}$, where $t$ is average rise time of amperometric events, and $\tau$ is time constant of the interval between each peptide and the preceding amperometric event. This approach relies on secretion following a Poisson distribution (see Bruns et al., 2000). For the cell shown in Figure $2 B$, the distribution of interevent intervals was fit with a single exponential, giving a time constant of $468 \mathrm{~ms}$ (Fig. $4 \mathrm{~B}$ ). The average rise time of the amperometric spikes was $2.4 \pm 2.2 \mathrm{~ms}(n=71)$. The likelihood that one or more events would occur within a $3 \mathrm{~ms}$ window was $p=0.006$. Thus, both methods indicate that the overlapping events are most likely caused by the corelease of catecholamines and peptide from a single granule rather than the chance overlap of amperometric and peptidergic events.

\section{Discussion}

In this study, I examine the release of a classical transmitter and a neuropeptide from individual chromaffin cells. The primary finding is that a single LDCG can contain two classes of transmitters, which are released with a very similar time course.

Chromaffin cells synthesize, transport, and secrete the catecholamines and a variety of peptides (Wilson et al., 1982; Johns et al., 2001; Perrais et al., 2004). Whether peptides such as NPY can be present in the catecholamine-containing granules and coreleased is unclear [although electron microscopy (EM) studies have localized NPY to dense core granules] (Steiner et al., 1989). Because partial emptying of LDCGs can occur (Perrais et al., 2004; Fulop et al., 2005), the coexistence of multiple transmitters in the same organelle does not imply that all transmitters will be released once the fusion pore forms. Work on insulinsecreting cells has shown that nucleotides can be released promptly, whereas larger peptides are released more slowly (Obermuller et al., 2005).

Amperometry and FMRFamide tagging were used to simultaneously measure the secretion of the catecholamines and a peptide. This approach had two advantages. First, amperometric spikes reflect secretion from individual LDCGs (Wightman et al., 1991). Second, amperometry and FMRFamide tagging have a millisecond time resolution. Thus, transmitter release from single LDCGs was followed more rapidly than would be possible with fluorescent markers. Fortuitously, all chromaffin cells were found to be NPY immunoreactive. Therefore, it is likely that 
secretion was measured from cells that endogenously contained both NPY and the catecholamines. One consideration in experiments of this type is that overexpression could lead to the presence of the tag in LDCGs that do not normally contain peptides. This possibility is difficult to eliminate because even minor mistargeting might be detected (the electrophysiological approach can detect secretion from a single granule).

When secretion was evoked, co-occurring amperometric spikes and peptidergic secretory currents were observed. By applying two independent methods, it was determined that these events were unlikely to have occurred at the same time by chance. It therefore appears that in chromaffin cells some granules can contain both classical and peptide transmitters, and these can be released virtually simultaneously.

From measurements of the rise time of the secretory events, peptide release from a single LDCG was delayed compared with the catecholamines by $<1-2 \mathrm{~ms}$. However, this value is an upper estimate because the kinetics of the peptidergic events are probably distorted by a diffusional delay between peptide release and receptor activation. The decay of the amperometric events was significantly faster than that of the peptidergic events. This is expected because the amperometric signal is self-limiting (transmitter oxidation leads to loss of the detectable molecule). In contrast, decay of the peptidergic signal is likely to involve diffusion and peptidase-dependent destruction of the peptide tag.

Although co-occurring catecholamine and peptidergic secretory events were observed, why were these events only a fraction of the total number recorded? The amperometric electrode selectively monitors secretory events occurring close to the probe, estimated at $6-25 \%$ of the total number of secretory events (Chow et al., 1992; Grabner et al., 2005). In contrast, FMRFamide tagging should sample events occurring over the entire surface of the cell. Thus, some peptide events would be observed in the absence of amperometric events. However, why are some amperometric events not associated with peptidergic events? One possibility is that these are LDCGs formed before transfection and thus would not contain any peptide tag. Depending on the cell type, the half-life of the catecholamines can be up to $18 \mathrm{~d}$ (Corcoran et al., 1984), whereas these experiments were conducted 3-4 d after transfection. Chromaffin cells contain $\sim 20,000$ dense core granules (Plattner et al., 1997), but the NPY immunoreactivity did not markedly overlap with that of $\mathrm{D} \beta \mathrm{H}$, suggesting that not all LDCGs contain NPY. The tendency for newly synthesized granules to be preferentially released (Duncan et al., 2003) may explain why cosecretory events are even observed. Although some individual LDCGs were found to contain both peptide and catecholamines, this does not mean that all granules contain both transmitter types. Sometimes considered to be homogenous, recent evidence indicates the presence of several populations of LDCGs in mouse chromaffin cells (Grabner et al., 2005).

Although this work indicates that the timing of peptide release can be comparable with that of classical transmitters, the rate of release is likely to depend on the particular peptide. The time course of transmitter release will be affected by the diameter of the fusion pore and the molecular weight of the transmitter. Because the rate of diffusion is inversely proportional to the cube root of the molecular weight (MW), epinephrine (MW, 183Da) would theoretically diffuse $\sim 1.5$ times as rapidly as FMRFamide (MW, 599Da). The molecular weight of FMRFamide is comparable with that of met-enkephalin (MW, 574Da), an endogenous peptide in chromaffin cells, but less than that of NPY (MW, $4272 \mathrm{Da})$. However, other factors such as interactions with the granule matrix are also likely to regulate the rate at which transmitter leaves a fusing granule.

In conclusion, these results support the idea that single LDCGs can contain multiple classes of transmitters and that some peptides can exit a fusing granule as rapidly as classical transmitters.

\section{References}

Angleson JK, Cochilla AJ, Kilic G, Nussinovitch I, Betz WJ (1999) Regulation of dense core release from neuroendocrine cells revealed by imaging single exocytic events. Nat Neurosci 2:440-446.

Barg S, Olofsson CS, Schriever-Abeln J, Wendt A, Gebre-Medhin S, Renstrom E, Rorsman P (2002) Delay between fusion pore opening and peptide release from large dense-core vesicles in neuroendocrine cells. Neuron 33:287-299.

Blaschko H, Welch AD (1953) Localization of adrenaline in cytoplasmic particles of the bovine adrenal medulla. Naunyn Schmiedebergs Arch Exp Pathol Pharmakol 219:17-22.

Bruns D, Riedel D, Klingauf J, Jahn R (2000) Quantal release of serotonin. Neuron 28:205-220.

Chow RH, von Rüden L, Neher E (1992) Delay in vesicle fusion revealed by electrochemical monitoring of single secretory events in adrenal chromaffin cells. Nature 356:60-63.

Corcoran JJ, Wilson SP, Kirshner N (1984) Flux of catecholamines through chromaffin vesicles in cultured bovine adrenal medullary cells. J Biol Chem 259:6208-6214.

Dacheux F (1981) Ultrastructural localization of corticotropin, betalipotropin, and alpha- and beta-endorphin in the porcine anterior pituitary. Cell Tissue Res 215:87-101.

Duncan RR, Greaves J, Wiegand UK, Matskevich I, Bodammer G, Apps DK, Shipston MJ, Chow RH (2003) Functional and spatial segregation of secretory vesicle pools according to vesicle age. Nature 422:176-180.

Fisher JM, Sossin W, Newcomb R, Scheller RH (1988) Multiple neuropeptides derived from a common precursor are differentially packaged and transported. Cell 54:813-822.

Fulop T, Radabaugh S, Smith C (2005) Activity-dependent differential transmitter release in mouse adrenal chromaffin cells. J Neurosci 25:7324-7332.

Gammelsaeter R, Froyland M, Aragon C, Danbolt NC, Fortin D, StormMathisen J, Davanger S, Gundersen V (2004) Glycine, GABA and their transporters in pancreatic islets of Langerhans: evidence for a paracrine transmitter interplay. J Cell Sci 117:3749-3758.

Glombik MM, Gerdes HH (2000) Signal-mediated sorting of neuropeptides and prohormones: secretory granule biogenesis revisited. Biochimie 82:315-326.

Grabner CP, Price SD, Lysakowski A, Fox AP (2005) Mouse chromaffin cells have two populations of dense core vesicles. J Neurophysiol 94:2093-2104.

Graham ME, O'Callaghan DW, McMahon HT, Burgoyne RD (2002) Dynamin-dependent and dynamin-independent processes contribute to the regulation of single vesicle release kinetics and quantal size. Proc Natl Acad Sci USA 99:7124-7129.

Henion PD, Landis SC (1990) Asynchronous appearance and topographic segregation of neuropeptide-containing cells in the developing rat adrenal medulla. J Neurosci 10:2886-2896.

Johns LM, Levitan ES, Shelden EA, Holz RW, Axelrod D (2001) Restriction of secretory granule motion near the plasma membrane of chromaffin cells. J Cell Biol 153:177-190.

Kreiner T, Sossin W, Scheller RH (1986) Localization of Aplysia neurosecretory peptides to multiple populations of dense core vesicles. J Cell Biol 102:769-782.

Lewis EJ, Asnani LP (1992) Soluble and membrane-bound forms of dopamine beta-hydroxylase are encoded by the same mRNA. J Biol Chem 267:494-500.

Mosharov EV, Sulzer D (2005) Analysis of exocytotic events recorded by amperometry. Nat Methods 2:651-658.

Obermuller S, Lindqvist A, Karanauskaite J, Galvanovskis J, Rorsman P, Barg $S$ (2005) Selective nucleotide-release from dense-core granules in insulin-secreting cells. J Cell Sci 118:4271-4282.

Perrais D, Kleppe IC, Taraska JW, Almers W (2004) Recapture after exocytosis causes differential retention of protein in granules of bovine chromaffin cells. J Physiol (Lond) 560:413-428.

Plattner H, Artalejo AR, Neher E (1997) Ultrastructural organization of bo- 
vine chromaffin cell cortex-analysis by cryofixation and morphometry of aspects pertinent to exocytosis. J Cell Biol 139:1709-1717.

Steiner HJ, Schmid KW, Fischer-Colbrie R, Sperk G, Winkler H (1989) Colocalization of chromogranin A and B, secretogranin II and neuropeptide $\mathrm{Y}$ in chromaffin granules of rat adrenal medulla studied by electron microscopic immunocytochemistry. Histochemistry 91:473-477.

Urban L, Randic M (1984) Slow excitatory transmission in rat dorsal horn: possible mediation by peptides. Brain Res 290:336-341.

Whim MD, Lloyd PE (1989) Frequency-dependent release of peptide cotransmitters from identified cholinergic motor neurons in Aplysia. Proc Natl Acad Sci USA 86:9034-9038.

Whim MD, Moss GW (2001) A novel technique that measures peptide se- cretion on a millisecond timescale reveals rapid changes in release. Neuron 30:37-50.

Wightman RM, Jankowski JA, Kennedy RT, Kawagoe KT, Schroeder TJ, Leszczyszyn DJ, Near JA, Diliberto Jr EJ, Viveros OH (1991) Temporally resolved catecholamine spikes correspond to single vesicle release from individual chromaffin cells. Proc Natl Acad Sci USA 88:10754-10758.

Wilson SP, Chang KJ, Viveros OH (1982) Proportional secretion of opioid peptides and catecholamines from adrenal chromaffin cells in culture. J Neurosci 8:1150-1156.

Zhang X, Nicholas AP, Hokfelt T (1993) Ultrastructural studies on peptides in the dorsal horn of the spinal cord. I. Co-existence of galanin with other peptides in primary afferents in normal rats. Neuroscience 57:365-384. 